\title{
Manifestações de Bullying em Diferentes Contextos Escolares: um Estudo Exploratório
}

\author{
Luís Gustavo Faria Aguiar \\ Faculdade de Filosofia, Ciências e Letras de Ribeirão \\ Preto (FFCLRP-USP). São Paulo, Brasil.
}

\author{
Sylvia Domingos Barrera \\ Faculdade de Filosofia, Ciências e Letras de Ribeirão \\ Preto (FFCLRP-USP). São Paulo, Brasil.
}

\begin{abstract}
Resumo: A violência entre pares tem assumido destaque na literatura educacional em função de sua frequência de ocorrência e dos efeitos deletérios sobre os envolvidos. O objetivo geral desta pesquisa foi explorar a ocorrência de bullying em dois contextos escolares - público e privado -, comparando-as em termos de frequência e padrões de ocorrência do fenômeno. Os sujeitos da pesquisa foram 76 alunos do $6^{\circ}$ ao $9^{\circ}$ ano do Ensino Fundamental, com idade variando entre 10 e 15 anos, sendo $54 \%$ da amostra do sexo feminino. Os participantes responderam anonimamente a um questionário que visava obter informações referentes à ocorrência de agressões entre pares na escola, bem como identificar o envolvimento dos respondentes nessas situações. Os resultados indicaram que $24 \%$ dos participantes consideram-se vítimas de agressões repetidas, o que poderiam configurar episódios de bullying. Foi observada maior frequência de agressores do sexo masculino na escola pública, enquanto na particular não houve diferenças significativas quanto ao sexo dos agressores. Em ambas as escolas encontrou-se elevada incidência de agressões, tanto nos recreios quanto em sala de aula, sendo a atitude passiva predominante entre os observadores. Discute-se a necessidade de as escolas investirem em estratégias visando a prevenção e o enfrentamento do problema.
\end{abstract}

Palavras-chave: Bullying, Violência Escolar, Ensino Fundamental.

\section{Manifestations of Bullying in Different School Contexts: an Exploratory Study}

Abstract: Peers' violence has been a prominent theme in the educational literature due to its frequency and deleterious effects on those involved. The general objective of this research was to explore the occurrence of bullying in two school contexts - public and private - comparing them in terms of frequency and patterns of occurrence of the phenomenon. The subjects were 76 students from $6^{\text {th }}$ to $9^{\text {th }}$ degree of elementary school, aged between 10 and 15 years old, $54 \%$ of the sample beingfemale. The participants answered anonymously a survey for obtaining information regarding the occurrence of aggressions at school, as well as for identifying the participants' involvement in these situations. Results indicated that $24 \%$ of the participants consider themselves victims of repeated aggressions that could configure bullying episodes. It was observed a higher frequency of male aggressors in the public school while in private school no significant differences were found between the aggressors' sexes. In both of schools a high incidence of aggressions at break time and in the classrooms was found, with the most of witnesses having a passive behavior. We discuss the need of schools' investment in strategies aiming to prevent and minimize the problem.

Keywords: Bullying, School Violence, Elementary Education. 


\title{
Manifestaciones de Bullying en Diferentes Contextos Escolares: un Estúdio Exploratório
}

\begin{abstract}
Resumen: La violencia entre pares se ha destacado en la literatura educativa en función de su frecuente ocurrencia y de los efectos deletéreos sobre los involucrados. El objetivo general de esta investigación fue explorar la ocurrencia de bullying en dos contextos escolares - público y privado - comparándolos en términos de frecuencia y patrones de ocurrencia del fenómeno. Los sujetos del estudio fueron 76 alumnos de $6^{\circ}$. a $9^{\circ}$. año de la escuela primaria, con edades comprendidas entre los 10 y 15 años, de los cuales 54\% eran mujeres. Los participantes respondieron anónimamente un cuestionario para identificar situaciones de agresión en la escuela, así como su propia participación en estas situaciones. Los resultados indicaron que $24 \%$ de los encuestados se consideran a sí mismos víctimas de agresiones repetidas que podrían constituir episodios de bullying. Se encontró mayor frecuencia de agresores hombres en la escuela pública, mientras que en la escuela privada no se encontraron diferencias significativas entre los sexos de los agresores. En ambos tipos de escuelas hubo alta incidencia de agresiones durante el recreo y en el aula y la mayoría de los observadores tuvo comportamiento pasivo. Se concluye que las escuelas necesitan crear estrategias para prevenir y abordar el problema.
\end{abstract}

Palabras clave: Bullying, Violencia Escolar, Escuela Primaria.

\section{Introdução}

Em seu artigo destinado a realizar um balanço das pesquisas sobre o tema da violência escolar no Brasil após 1980, Sposito (2001) concluiu que as principais modalidades do fenômeno se apresentam na forma de ações contra o patrimônio escolar e de agressões pessoais, sobretudo entre os próprios alunos. Estas últimas ganham maior visibilidade nas pesquisas a partir da década de 1990, não se restringindo às escolas públicas, mas atingindo também escolas particulares, destinadas às elites.

Assim, pode-se afirmar que uma das manifestações da violência escolar que tem assumido grande destaque, tanto no Brasil quanto em outros países, é a agressão entre alunos, particularmente o fenômeno conhecido por bullying, o qual, apesar de não ser um problema recente, somente na atualidade vem recebendo maior atenção dos pesquisadores. $\mathrm{O}$ termo bullying pode ser definido como comportamentos negativos intencionais, que ocorrem repetidamente e ao longo do tempo contra uma pessoa com dificuldades de se defender sozinha desses ataques (Olweus, 1993; 2011). Ainda, de acordo com Pearce e Thompson (1998), outras características do fenômeno envolveriam uma relação desigual de poder entre o praticante e a vítima, além do uso deliberado de agressão para causar dor física ou angústia emocional. O desequilí- brio de poder pode estar relacionado à menor estatura ou força física da vítima, ao fato desta estar em minoria e/ ou à sua falta de assertividade (Fante, 2005).

Os primeiros estudos sistemáticos sobre bullying foram realizados por Dan Olweus, na Noruega, tendo sido publicados no início da década de 1990. Apesar da distância em termos espaciais e temporais, com relação à realidade escolar brasileira, muitos dos resultados obtidos por esse pesquisador têm se mostrado válidos para analisar o fenômeno no Brasil $\mathrm{e}$ têm sido corroborados por estudos brasileiros sobre o tema. Com efeito, no que se refere ao mapeamento do problema no Brasil, de forma mais sistemática, temos o estudo realizado pela Abrapia (Associação Brasileira Multiprofissional de Proteção à Infância e à Adolescência) no biênio 2002/2003, em 11 escolas do Rio de Janeiro, com a participação de 5.800 alunos de $5^{\mathrm{a}}$ a $8^{\mathrm{a}}$ séries (Lopes Neto, 2005; 2007). Além desse levantamento, outro importante trabalho sobre o tema em contexto nacional é o livro de Fante (2005), que aborda, além de questões conceituais relacionadas ao bullying, resultados de pesquisa da autora sobre o fenômeno, bem como o programa por ela elaborado denominado "Educar para a Paz", cujas estratégias mostraram-se eficazes na redução do problema.

Os estudiosos do fenômeno bullying costumam distinguir e atribuir características diferentes aos diver- 
sos atores envolvidos. Os "autores" ou "agressores" são aqueles que praticam o bullying, os quais foram caracterizados como tendo boa autoestima, serem insensíveis aos sentimentos dos outros, serem fortes física e emocionalmente, apresentarem fraco controle de impulsos, elevado grau de agressividade e desejo de domínio, além de perceberem a violência como uma qualidade (Pearce, \& Thompson, 1998). Olweus (1993) enfatiza que uma discrepância de força física entre agressores e vítimas costuma estar presente nestas relações, mas considera que esta não é o fator determinante, pois juntamente com a força deve combinar-se um padrão agressivo de reação. Esse autor lembra ainda que a prática de bullying apresenta relação com fatores da criação familiar, como conflitos frequentes, discórdia e discussões abertas entre os pais, os quais podem criar relações inseguras para a criança. Além desses aspectos, a presença de violência doméstica e de excesso de permissividade constituem padrões familiares que têm sido relacionados à prática do bullying (Lopes Neto, 2005; 2007).

Examinando agora questões ambientais que não possuem relação com o problema, Olweus (1993) cita o nível socioeconômico dos estudantes. No Brasil, estudos como o de Francisco e Libório (2008) também não encontraram diferenças significativas entre a incidência de bullying comparando escolas centrais e de periferia. Na mesma direção, Calbo, Busnello, Rigoli, Schaefer e Kristensen (2009) e Fante (2005) encontraram elevada incidência do problema em pesquisas realizadas com alunos da rede particular de ensino, rejeitando a hipótese de que o baixo nível socioeconômico seja um fator agravante do problema.

Olweus (1993) também relata alguns fenômenos de grupo que podem aumentar a ocorrência de comportamentos agressivos, como a observação de modelos (que não são punidos, ou mesmo são recompensados), a diminuição do sentimento de responsabilidade individual nas ações grupais (nas quais a responsabilidade é "diluída" pelo grupo) e, por fim, as mudanças da percepção do grupo em relação à vítima com o passar do tempo, como resultado dos ataques e comentários degradantes de ocorrência repetitiva.

As "vítimas" ou os "alvos" podem ser qualificados como os alunos que são expostos a ações negativas por parte de outros estudantes, que podem manifestar-se na forma de contato físico, exclusão do grupo, abuso verbal, calúnias, gestos rudes, dentre outros comportamentos que expressam este tipo de violên- cia (Moura, Cruz, \& Quevedo, 2011). Outros autores destacam ainda que os ataques não possuem motivação aparente (Lisboa, Braga, \& Ebert, 2009). Segundo Olweus (1993), apesar da suposição difundida de que “diferenças” físicas (por exemplo: usar óculos, ser obeso etc.) sejam fatores que predispõem alguém a se tornar uma vítima, essa hipótese não teve suporte em suas pesquisas, ou seja, embora seja possível que, em casos particulares, o bullying possa ocorrer devido a algum aspecto da aparência da vítima, esta não é a causa do fenômeno de um modo geral. Também segundo o autor, as vítimas não costumam ser agressivas, geralmente são cuidadosas, sensíveis e quietas, normalmente apresentando um perfil de baixa autoestima. Pearce e Thompson (1998) também listam algumas características de crianças pré-dispostas a se tornarem vítimas, que incluem aspectos como: temperamento ansioso, baixa autoestima, insegurança, falta de amigos, ser reativo emocionalmente, facilmente dominado e particularmente não agressivo. De acordo com Lopes Neto (2005), alguns padrões educativos familiares associados a esse tipo de comportamento seriam: superproteção, tratamento infantilizado ou mesmo de "bode expiatório" da família.

Além dos autores e vítimas "típicos", há ainda os chamados "alvo-autores", os quais, além de sofrerem agressões, apresentam também comportamento agressivo e provocador (Freire, \& Aires, 2012). Estes, a quem Olweus (1993) chama de "vítimas provocativas", são caracterizados por uma combinação de padrões de reação de ansiedade e agressividade, podendo apresentar comportamento hiperativo, o que pode gerar irritação e tensão ao seu redor, provocando muitos de seus pares. Por fim, existem os "espectadores" ou "testemunhas", que não atuam diretamente, mas que fazem parte do contexto por presenciarem as cenas de bullying (Freire, \& Aires, 2012). Embora não participem diretamente das ações, estes podem sofrer com o medo, a dúvida e a descrença nas ações que a escola pode tomar a respeito do problema (Lopes Neto, 2007). Podem ainda, mesmo que não seja sua intenção, reforçar as práticas de violência ao não se envolver e não tomar partido com os atores (vítima ou agressor), permitindo que o bullying continue, ao dar tal aprovação silenciosa; além disso, podem servir de audiência para o agressor no momento dos ataques, podendo ainda encorajá-lo, ao rir, ou com algum outro gesto que sirva de aprovação (Salmivalli, 1999). 
Uma diferenciação que tem sido feita na análise do fenômeno diz respeito ao bullying direto e indireto. O primeiro inclui comportamentos como agressões físicas, abusos sexuais, insultos, apelidos, comentários racistas e prejuízo à propriedade material alheia, ou seja, ataques indisfarçados. Já a forma indireta envolve exclusão intencional de uma pessoa do grupo e outros comportamentos, como fofocas, que marginalizam e isolam o outro, além de qualquer tipo de manipulação de um indivíduo ou um grupo contra seus pares (Olweus, 1993; Smith \& Sharp, 1995, citados por Calbo et al., 2009). Nos últimos anos, uma nova modalidade de bullying vem se destacando, o cyberbullying, que faz uso das tecnologias - especialmente as de comunicação - para os ataques, utilizando recursos de celulares, internet, fotos digitais e sites pessoais difamatórios, tendo o anonimato como um dos motivadores para os praticantes (Lopes Neto, 2005; 2007).

Quanto aos locais de ocorrência do bullying, algumas pesquisas encontraram lugares e situações no ambiente escolar onde a ocorrência de bullying parece ser maior, especialmente nos recreios (Pereira, Silva \& Nunes, 2009; Raimundo, \& Seixas, 2009). Olweus (1993) também considera o recreio um ambiente crítico, sobretudo quando é mal supervisionado. A sala de aula também tem sido apontada, em algumas pesquisas brasileiras, como um ambiente com elevada frequência de práticas de bullying (Fante, 2005; Francisco, \& Libório, 2008; Lopes Neto, 2005; 2007).

É importante lembrar que existem fatores externos à escola, oriundos da própria família, capazes de influenciar tanto o surgimento quanto a resolução do problema, como apontam Pearce e Thompson (1998), os quais alegam que muitas ações de prevenção ao bullyingdeveriam começar em casa, antes de a criança ingressar na escola. Para estes autores, os adultos devem dar exemplos de bons relacionamentos, terem eles mesmos um bom autocontrole, ensinar a criança que a violência é inaceitável, identificar e nomear os efeitos da agressividade, descrever o que a vítima de agressão sente, além de estimular o desenvolvimento de atitudes de empatia.

A empatia pode ser entendida como a capacidade de compreender e compartilhar a experiência emocional do outro, comunicando-lhe adequadamente tal compreensão e sentimento (Del Prette, \& Del Prette, 2005). É possível distinguir ainda diferentes aspectos deste constructo, sendo um o cognitivo e o outro, o afetivo. Cognitivamente falando, a empatia envolve as habilidades de reconhecer as emoções dos outros e de compartilhar de suas perspectivas, enquanto o componente afetivo da empatia diz respeito à capacidade de compartilhar dos sentimentos de outrem (Caravita, Di Blasio, \& Salmivalli, 2008). Dados empíricos sugerem que a primeira forma pode estar presente mesmo em agressores, que fariam uso da habilidade de reconhecer o estado emocional dos outros para realizar as agressões, manipulando o comportamento destes. Por outro lado, a empatia emocional estaria mais fortemente associada à defesa dos agredidos (Caravita et al., 2008).

No que se refere às origens do comportamento agressivo, estudos tem sugerido que, de um modo geral, aspectos familiares e o próprio temperamento da criança poderiam influir no aumento da agressividade, favorecendo a assunção de um papel de agressor (Olweus, 1993). Alguns fatores pessoais associados à prática do bullying, segundo Lopes Neto (2005), seriam: hiperatividade, impulsividade, distúrbios comportamentais, dificuldades de atenção e desempenho escolar deficiente. Fante (2005) destaca ainda, além desses, a falta de empatia.

No entanto, a escola também pode ter uma influência no surgimento e na resolução dessa problemática. De acordo com Pearce e Thompson (1998), atitudes de agressão por parte das crianças costumam aparecer com maior frequência em escolas com baixo nível de estado de ânimo entre os funcionários, métodos de disciplina inconsistentes, padrões confusos sobre normas de comportamentos e falta de supervisão adequada nos recreios. Esta, quando insuficiente, permite que o bullying aconteça, mas, quando adequada, pode impedir que maiores danos sejam causados, por garantir a possibilidade de lidar com o problema de imediato.

Segundo Lemos (2007), o bullying pode gerar problemas de desempenho escolar para a vítima, já que o objeto de desejo de aprendizagem passa a ser objeto de repulsa, desmotivando o aluno, que inventa motivos para faltar à escola, não presta atenção às aulas, além de não fazer as tarefas e ter sua socialização comprometida, o que pode levar à reprovação e ao abandono escolar. Da mesma forma, os observadores podem passar a focar sua atenção cada vez mais nos episódios de agressão e cada vez menos na escola, o que também pode prejudicar o aprendizado (Lopes Neto, 2007).

Freire, Simão e Ferreira (2006) também defendem que as situações de agressividade com as quais as crianças são confrontadas no seu cotidiano esco- 
lar e com as quais não sabem lidar (sendo elas vítimas ou observadores) por vezes afetam seus percursos escolares, desenvolvimento pessoal e social, bem como influenciam nas condições de seu bem-estar. Mesmo os agressores apresentam problemas posteriormente, como Olweus (2011) demonstrou em sua pesquisa sobre a relação entre criminalidade e bullying. Segundo este autor, padrões agressivos de comportamento como os caracterizados nestes episódios, representam um indicador de sérios problemas antissociais para muitos dos agressores em fases posteriores de suas vidas, o que foi demonstrado pelo alto índice de jovens agressores que apresentaram registro criminal mais tarde. Por outro lado, estudos de seguimento (follow up) indicam que as vítimas têm maior tendência, quando adultas, a apresentar depressão e baixa autoestima (Freire et al., 2006). Além disso, tendências suicidas e mesmo homicidas também têm sido observadas (Fante, 2005).

É válido ressaltar que, embora o fenômeno não seja novo, a preocupação com o bullying é relativamente recente (Fante, 2005). Os estudos sobre esse tema começaram há cerca de 30 anos e só ganharam mais força nas últimas duas décadas, graças às pesquisas que evidenciam sua prevalência e os riscos que apresentam para os jovens e instituições, afetando o seu desenvolvimento (Lisboa, Braga, \& Ebert, 2009). Segundo Olweus (1993), dados de um estudo nacional realizado na Noruega na década de 1980, envolvendo alunos de 8 a 16 anos, indicaram que $15 \%$ da população escolar estaria envolvida diretamente com problemas de bullying (cerca de $9 \%$ como vítimas e $7 \%$ como agressores). No Brasil, o levantamento realizado pela ABRAPIA indicou que cerca de $40 \%$ dos adolescentes pesquisados admitiram ter-se envolvido diretamente em situações de bullying, seja como alvos, agressores ou alvos-agressores (Lopes Neto, 2005; 2007).

Vários estudos têm apontado diferenças quanto ao gênero na prática do bullying. Em geral os meninos têm sido reportados como mais frequentemente envolvidos como agressores, porém essa prevalência não é observada no que se refere às vítimas, que tendem a se distribuir de forma relativamente equivalente entre os sexos (Lopes Neto, 2005; 2007; Bandeira \& Hutz, 2012). Outra diferença observada é que os meninos tendem a ser agredidos por meninos, enquanto as meninas são agredidas tanto por meninos quanto por meninas (Francisco \& Libório, 2008; Bandeira, \& Hutz, 2012). Além disso, de acordo com
Lopes Neto (2005, 2007), enquanto os meninos tendem a se envolver mais frequentemente em situações de bullying direto (agressões físicas e/ou verbais), o padrão de bullying praticado pelas meninas costuma ser o indireto (difamações e exclusões).

Ainda de acordo com alguns autores (Lopes Neto, 2005; 2007), a incidência maior do problema ocorre na faixa etária entre os 11 e 13 anos, o que corresponde ao período do $2^{\circ}$ ciclo do Ensino Fundamental, sendo bem menos frequente entre alunos da Educação Infantil ou do Ensino Médio. Sendo assim e, levando-se em conta a possível discrepância de idade entre vítimas e agressores, os quais têm sido identificados, em algumas pesquisas, como frequentemente sendo mais velhos do que suas vítimas (Bandeira, \& Hutz, 2012; Lopes Neto, 2007; Olweus, 1993), o Ensino Fundamental parece constituir o período de maior risco para a eclosão do problema, o que justifica que a maioria dos estudos tenha se voltado para o mapeamento do fenômeno nesse nível de ensino.

Uma das razões para que os estudos sobre este assunto só tenham apresentado maior força nestes últimos anos é a diferença tênue entre bullying e brincadeira para os observadores externos, o que provavelmente fez com que o problema passasse muito tempo despercebido ou, pelo menos, fosse minimizado. No entanto, um dos critérios de identificação do fenômeno é o sofrimento que supostas brincadeiras possam causar a outrem: havendo sofrimento, caracteriza-se aí um quadro de bullying (Lisboa, Braga \& Ebert, 2009).

Considerando a importância do problema em termos de sua frequência e possíveis consequências nocivas para o desenvolvimento emocional e acadêmico dos envolvidos, bem como algumas questões que ainda persistem sobre o padrão de comportamento dos envolvidos em termos de sexo e sobre possíveis influências do nível socioeconômico sobre a prática de bullying, o objetivo geral desta pesquisa foi explorar a ocorrência de bullying em dois contextos escolares diversos - um público e outro privado-, analisando possíveis semelhanças e/ou diferenças entre eles, em termos de frequência e padrões de ocorrência, incluindo o sexo dos atores, buscando contribuir para uma maior compreensão do fenômeno.

\section{Método}

A pesquisa seguiu um delineamento metodológico que pode ser caracterizado como levantamento ou survey. Este foi realizado através da obtenção de 
dados diretamente relacionados ao mapeamento do fenômeno do bullying em contextos escolares diferenciados (escola pública e privada), através da aplicação de um questionário.

\section{Participantes}

Os dados foram coletados em duas escolas do Ensino Fundamental, uma pública e uma particular, localizadas em uma cidade do interior do estado de São Paulo e escolhidas por conveniência. Foram convidados a responderem a um questionário sobre o tema do bullying todos os alunos do ciclo II ( $6^{\circ}$ ao $9^{\circ}$ ano) do período matutino das referidas escolas. No total, 76 alunos participaram da pesquisa, 57 da escola pública e 19 da privada. A idade dos participantes variou de 10 a 15 anos, com média de idade de 12,3 anos ( $\mathrm{dp}=1,21)$ na escola pública e 11,8 anos $(\mathrm{dp}=1,27)$ na escola privada. Dados sobre o sexo e série dos participantes encontram-se na Tabela 1, apresentada a seguir. Observa-se reduzido número de alunos do $9^{\circ}$ ano, o que pode ser explicado pelo fato de que apenas a escola particular possuía, no momento da pesquisa, essa série escolar e, mesmo nessa escola, houve poucos participantes dessa sala.

\section{Instrumento}

O questionário aplicado, destinado à obtenção de informações sobre a frequência e natureza do problema do bullying nos contextos escolares pesquisados, foi elaborado em Portugal por Freire et al. (2006), tendo sido realizadas, pelos pesquisadores, pequenas adaptações de linguagem à realidade brasileira. As perguntas buscam informações a respeito de possíveis situações de bullying, visando investigar o problema a partir da percepção de cada ator envolvido (vítima, observador e agressor). A maior parte das questões são fechadas, envolvendo respostas do tipo "sim" ou "não" ou o assinalamento de uma opção dentre respostas previamente oferecidas, porém o questionário contém também algumas questões abertas a respeito de como os alunos percebem as relações humanas e o fenômeno da agressividade na escola.

\section{Procedimentos}

Os questionários foram aplicados na escola pública, em sala de aula, com duração de cerca de uma hora em cada turma. Já na escola particular, a aplicação se deu em uma sala separada e durou cerca de uma hora também. Em ambas as escolas o pesquisador ficou à disposição dos alunos durante a aplicação do questionário para esclarecer quaisquer dúvidas que pudessem surgir na resposta às questões.

\section{Procedimentos éticos}

O Projeto foi submetido ao Comitê de Ética em Pesquisa, tendo sido aprovado (CAAE $\mathrm{n}^{\circ}$ 20844713.3.0000.5407). Para participar da pesquisa os alunos precisaram trazer o Termo de Consentimento Livre e Esclarecido (TCLE) assinado pelos pais ou responsáveis, além de assinarem também um Termo de Assentimento, por se tratarem de adolescentes.

\section{Análise dos dados}

Os resultados obtidos com a aplicação do questionário foram submetidos a análises quantitativas descritivas e inferenciais. Foi utilizado o programa SPSS (Statistical Package for Social Sciences) para a realização das análises estatísticas, que visaram comparar os dados obtidos nas duas diferentes instituições e verificar a significância das diferenças encontradas

Tabela 1.

Frequência de participantes de acordo com a escola, a série e o sexo.

\begin{tabular}{lccccc}
\hline \multirow{2}{*}{ Série } & \multicolumn{2}{c}{ Escola 1 (pública) } & \multicolumn{2}{c}{ Escola 2 (particular) } & \multirow{2}{*}{ Total } \\
\cline { 2 - 5 } & Sexo masculino & Sexo feminino & Sexo masculino & Sexo feminino & \\
\hline $6^{\text {o }}$ ano & 17 & 8 & 1 & 4 & $30(40 \%)$ \\
$7^{\text {o }}$ ano & 6 & 2 & 3 & 5 & $16(21 \%)$ \\
$8^{\text {o }}$ ano & 5 & 19 & 3 & 2 & $29(38 \%)$ \\
$9^{\text {o }}$ ano & 0 & 0 & 0 & 1 & $1(1 \%)$ \\
Total & $28(49 \%)$ & $29(51 \%)$ & $7(37 \%)$ & $12(63 \%)$ & \\
& \multicolumn{2}{c}{$57(75 \%)$} & & & \\
\end{tabular}


entre ambas. Pelo fato de os dados obtidos corresponderem, em sua grande maioria, a variáveis qualitativas (nominais e ordinais), optou-se pela utilização de testes não paramétricos, adequados à comparação de dois grupos independentes (escola pública x particular ou sexo masculino $\mathrm{x}$ feminino). As questões abertas foram analisadas a partir de técnicas de análise de conteúdo, a fim de se construírem categorias de respostas com base em opiniões comuns.

\section{Resultados}

Devido ao grande número de análises estatísticas efetuadas, adotou-se como critério, na descrição dos resultados, apresentar os valores dos testes estatísticos apenas para as variáveis cuja análise identificou diferenças significativas $(\mathrm{p}<0,05)$ entre os grupos comparados.

$\mathrm{Na}$ análise das respostas da primeira parte do questionário, que envolvia a coleta de dados sociodemográficos, não foram encontradas diferenças significativas entre os participantes das duas escolas, a não ser quanto à profissão e escolaridade dos pais, bem como à etnia dos participantes. A Tabela 2 apresenta os resultados obtidos no teste de Qui-quadrado, realizado para a comparação das escolas, no que se refere a essas variáveis.

Os resultados indicam que, na escola pública, tanto no caso dos pais quanto das mães, predominaram ocupações associadas a trabalhos urbanos braçais e/ou pouco qualificados, como: empregadas domésticas, vigias, pedreiros, eletricistas, marceneiros, motoristas e vendedores. Já as ocupações mais frequentes dos pais e mães dos alunos da escola particular foram relacionadas a profissões de nível superior. Quanto à escolaridade, observou-se, entre os pais e mães de alunos da escola pública, predomínio do
Ensino Médio completo, enquanto na escola particular predominou o Ensino Superior completo.

No que se refere à etnia dos participantes, observou-se que esta característica mostrou-se significativamente associada à escola, destacando-se a inexistência de alunos negros e a maior frequência de alunos brancos na escola particular, bem como a maior porcentagem de alunos pardos na escola pública.

O segundo tópico do questionário era composto por duas questões abertas, uma que buscava saber a opinião dos participantes sobre o ambiente escolar e outra sobre o relacionamento entre as pessoas de suas respectivas turmas. $\mathrm{Na}$ análise dessas respostas, optou-se por classificar e quantificar as opiniões dos alunos, organizando-as em três categorias: a categoria "Bom" englobou as respostas com conteúdo expressando aspectos majoritariamente positivos, quer do ambiente escolar, quer das relações entre os colegas da classe; a categoria "Regular" agrupou as respostas ambíguas, isto é, que apontavam tanto características positivas quanto negativas; a categoria "Ruim" foi composta pelas respostas expressando aspectos majoritariamente negativos do ambiente escolar e/ou da relação da turma. Nesta parte do questionário predominou a categoria "Regular", com frequência superior a $50 \%$ nas duas escolas, seguida da categoria "Bom", com cerca de $30 \%$ de frequência em ambas as escolas, sendo que a categoria "Ruim" obteve apenas cerca de $10 \%$ da frequência de respostas. Como exemplos de aspectos positivos citados, temos: a ausência de brigas e discussões e o bom relacionamento entre alunos, funcionários e professores, na escola particular, e o incentivo por parte de autoridades da escola, a boa qualidade dos professores, a consideração do ambiente como educativo e a inclusão de esportes nas atividades escolares, na escola pública. Já com relação aos aspectos negativos é possível destacar respostas indicando agressões e desrespeito entre os colegas,

Tabela 2.

Resultados da comparação da ocupação e escolaridade dos pais e etnia dos alunos da escola pública e privada.

\begin{tabular}{lccccc}
\hline Variável & $\begin{array}{c}\text { Ocupação dos } \\
\text { pais }\end{array}$ & $\begin{array}{c}\text { Ocupação das } \\
\text { mães }\end{array}$ & $\begin{array}{c}\text { Escolaridade dos } \\
\text { pais }\end{array}$ & $\begin{array}{c}\text { Escolaridade das } \\
\text { mães }\end{array}$ & Etnia \\
\hline$\chi^{2}$ & 19,83 & 29,89 & 26,48 & 16,59 & 8,83 \\
$g l$ & 5 & 4 & 5 & 6 & 3 \\
$p$ & 0,001 & 0 & 0 & 0,011 & 0,032 \\
\hline
\end{tabular}


tanto na escola pública quanto na particular, além do desrespeito de alunos com relação aos professores na escola particular e de queixas com relação ao comportamento de certos professores, na escola pública.

O terceiro tópico do questionário buscava saber mais a respeito do bullying nas escolas, a partir do ponto de vista das possíveis vítimas. Inicialmente buscou-se mensurar a quantidade de alunos que relataram terem sido vítimas de agressão na escola, nas últimas duas semanas, obtendo-se porcentagens superiores na escola particular (78\% dos respondentes) com relação à escola pública ( $60 \%$ dos respondentes), porém sem diferenças significativas entre as escolas a esse respeito. Chama a atenção, no entanto, o número elevado de alunos da amostra pesquisada que se considera vítima de agressões no contexto escolar.

Na comparação dos tipos de agressões ocorridas nas escolas pesquisadas (Figura 1), observa-se que as queixas de humilhações e exclusões parecem ser um pouco mais frequentes na escola particular, enquanto as queixas de ameaças, empurrões, agressões físicas, roubo e abusos de ordem sexual são maiores na escola pública, ainda que essas diferenças não tenham sido estatisticamente significativas. No caso das ofensas (ou xingamentos) e calúnias, entretanto, foram observadas diferenças marginalmente significativas entre as escolas ( $\operatorname{com~} p=0,051$ e p $=0,05$, respectivamente). Nesses casos a tendência observada foi esse tipo de agressão ser mais frequentemente relatado pelos alunos da escola particular.
Quanto ao número de vezes que os alunos foram agredidos nas últimas duas semanas, observa-se que cerca de $39 \%$ da amostra da escola particular e de $19 \%$ da escola pública relatam ter sido vítimas de agressões repetidas, o que poderia configurar a ocorrência de bullying. Essa diferença observada entre as escolas também não atingiu significância estatística, sendo que os resultados obtidos indicam que, considerando a amostra total, $24 \%$ dos participantes, ou seja, praticamente um quarto dos alunos pesquisados, poderiam ser considerados vítimas de bullying.

Do ponto de vista dos alunos agredidos também não houve diferenças significativas entre as duas escolas quanto aos locais onde se deram as agressões, sendo que, em ambas, o recreio e a sala de aula são relatados como os locais em que há maior ocorrência de agressões, conforme pode ser observado na Figura 2. Chama a atenção, entretanto, a tendência à maior ocorrência de agressões em sala de aula na escola pública, sendo o recreio mais frequentemente apontado como local de ocorrência de bullying na escola particular.

Outra variável que não apresentou diferença significativa entre as escolas, mas cujo padrão de resultados chama a atenção, diz respeito às atitudes dos observadores relatadas pelas vítimas, sobretudo pela frequência das respostas "não fizeram nada" ou "riram", conforme pode ser visto na Figura 3.

Um aspecto que diferenciou as escolas foi o sexo do agressor $\left(X^{2}=13,476\right.$; g.l. $\left.=3 ; p=0,004\right)$, sendo que,

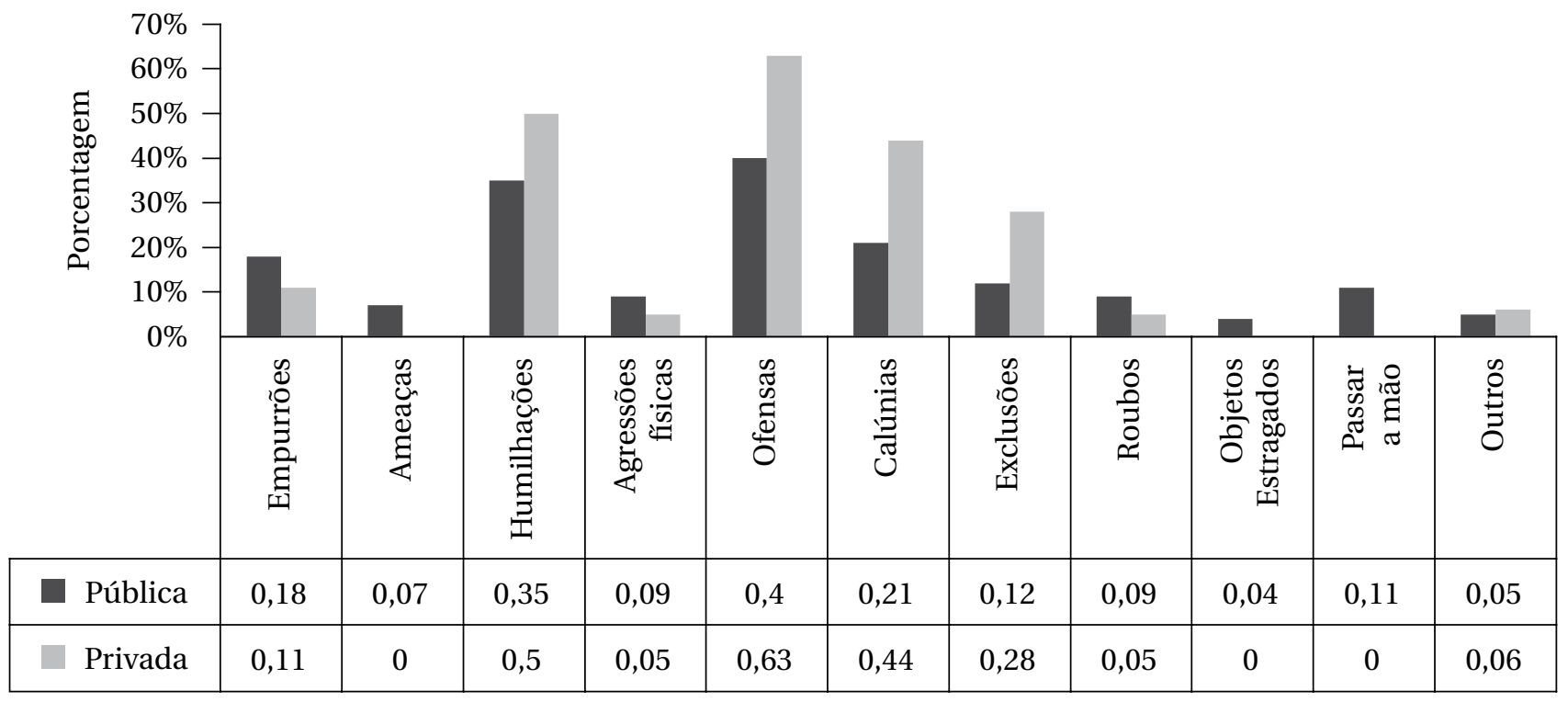

Figura 1.

Frequência e tipo de agressões de acordo com a escola 


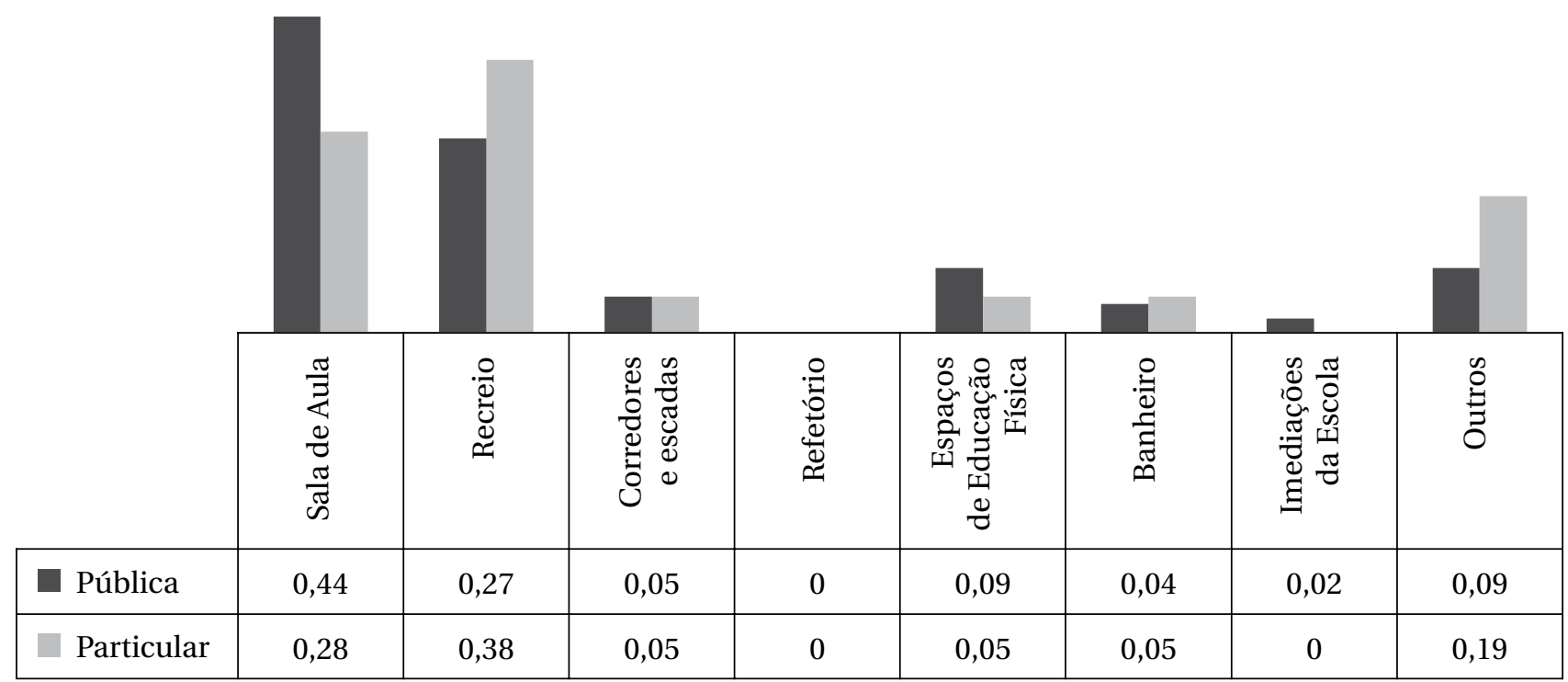

Figura 2.

Local de ocorrência das agressões

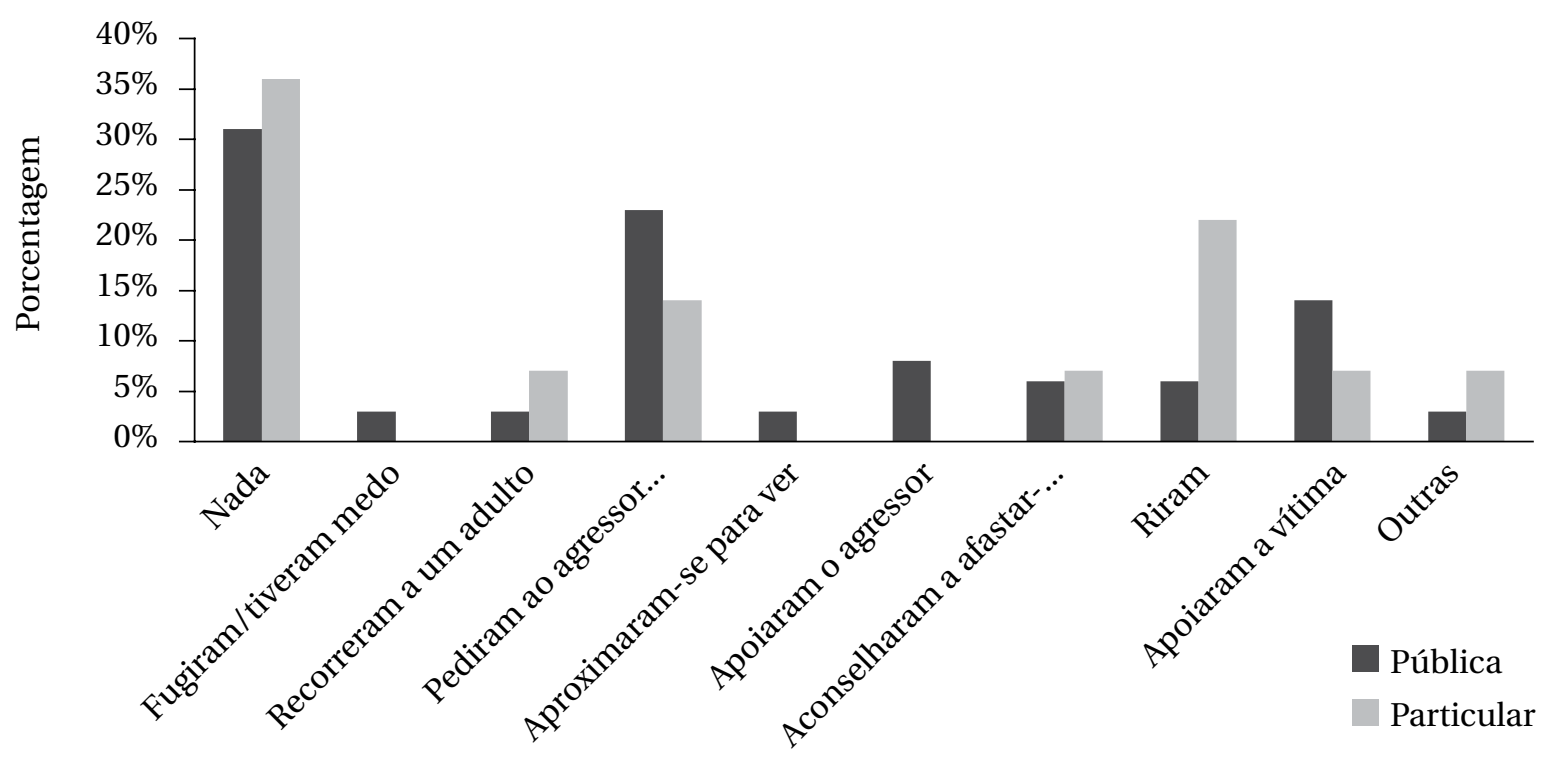

Figura 3.

Atitudes dos observadores relatadas pelas vítimas

na escola pública, predominaram as queixas de agressões efetuadas por alunos do sexo masculino (91\%), enquanto na particular as agressões são atribuídas de forma mais equilibrada tanto aos meninos (43\%), quanto às meninas (43\%).

Já na análise comparativa das respostas de acordo com o sexo dos participantes, a única variável que apresentou alguma associação com o sexo foi a relativa a ser vítima de algum tipo de agressão de um modo geral. Assim, de acordo com os resultados obti- dos, as meninas parecem sentir-se mais agredidas no contexto escolar do que os meninos, uma vez que $75 \%$ da amostra feminina relata sentir-se vítima de algum tipo de agressão, enquanto entre os meninos essa taxa é de 51\% ( $\mathrm{X}^{2}=4,501$; g.l. $\left.=1, \mathrm{p}=0,034\right)$.

No tópico referente às respostas de possíveis testemunhas, foram encontradas diferenças significativas entre as escolas para os itens que tratam sobre ameaças presenciadas $\left(\mathrm{X}^{2}=4,342\right.$; g.l.= $\left.1 ; \mathrm{p}=0,037\right)$, com maior frequência na escola pública, e também quanto 
às atitudes tomadas frente às situações de bullying $\left(X^{2}=28,462 ;\right.$ g.l. $\left.=8 ; p=0,016\right)$. Nesse último quesito, destacam-se, na escola pública, as respostas "pedi ao agressor para parar" e, na escola particular, "apoiei o agredido". É interessante destacar que, diferentemente da percepção das vítimas, os espectadores parecem perceber a si mesmos como tendo uma reação mais ativa e solidária frente às agressões presenciadas.

$\mathrm{Na}$ análise das respostas do setor do questionário referente à identificação de possíveis agressores, não foram encontradas diferenças significativas entre as escolas, tendo sido observado que um número elevado de participantes considera ter cometido agressões contra colegas nas últimas semanas, sendo $45 \%$ da amostra da escola pública e $31 \%$ da amostra da escola particular. Embora predominem as agressões esporádicas, ocorridas apenas uma vez nesse período, um número considerável de alunos - cerca de $14 \%$ do total de participantes - relata um padrão de agressões mais frequentes, as quais poderiam ser caracterizadas como bullying, caso sejam efetuadas de forma recorrente, com relação à(s) mesma(s) pessoa(s).

No que diz respeito ao número de alunos envolvidos nas agressões, predominam os episódios em que o agressor age sozinho (cerca de $60 \%$ dos casos), embora não sejam infrequentes também respostas de agressões cometidas em grupo. Esse padrão difere daquele obtido nos outros setores do questionário (vítimas e espectadores) nos quais predomina a percepção da agressão individual, o que suscita dúvidas sobre até que ponto risos por parte dos observadores poderiam ser considerados como cumplicidade pelos agressores.

Outro aspecto investigado foi a motivação para as agressões, sendo que os resultados indicam que tais comportamentos são encarados como "brincadeiras" pela maior parte dos agressores $(29 \%$ dos alunos da escola pública e $37 \%$ dos alunos da escola particular). Quanto ao sexo das vítimas, predominam, na concepção dos agressores de ambas as escolas, as violências cometidas contra os meninos. Coerentemente com as respostas obtidas em outras partes do questionário, a grande maioria das vítimas é percebida como tendo a mesma idade e também como fazendo parte da própria turma do agressor.

No que diz respeito à variável sexo, relacionada à percepção dos agressores, os resultados indicam que os alunos do sexo masculino consideram se envolver em mais episódios de agressão escolar do que as alu- nas, já que 58\% dos agressores autorreportados eram do sexo masculino e $42 \%$ do sexo feminino. Essa diferença, porém, não foi estatisticamente significativa.

\section{Discussão}

Os resultados do presente estudo vão ao encontro das conclusões de Sposito (2001), mostrando que a violência escolar entre alunos ocorre indistintamente, tanto nas escolas públicas como nas particulares, o que pôde ser observado, uma vez que poucas variáveis relativas aos episódios de violência mostraram diferenças significativas entre as escolas pesquisadas. Com efeito, no que diz respeito mais especificamente às possíveis situações de bullying vivenciadas pelos participantes da pesquisa, observou-se que tanto a frequência de vitimização quanto a de agressão não mostraram diferenças estatisticamente significativas na comparação entre as escolas. Se traçarmos um paralelo entre esses dados e a questão socioeconômica, encontramos então um argumento que reforça o que Olweus (1993) afirmou a respeito de o nível socioeconômico dos estudantes não ser um fator determinante dos comportamentos de bullying.

Por outro lado, as análises inferenciais relativas aos dados sociodemográficos demonstraram algumas diferenças significativas entre os alunos da escola pública e os da escola particular, sobretudo no que se refere à ocupação e escolaridade dos pais, bem como à etnia dos alunos. Tais resultados já eram esperados, uma vez que essas características estão diretamente associadas ao nível socioeconômico (Pastore, \& Silva, 2004), fator esse determinante da rede escolar frequentada pelos participantes.

Com relação aos dados obtidos pela amostra geral, observou-se que cerca de $24 \%$ dos participantes consideram ter sido agredidos duas ou mais vezes nas duas últimas semanas, o que configuraria prováveis episódios de bullying. Esse índice é superior aos 9\% de vítimas descrito por Olweus (1993) em sua pesquisa realizada na região da Escandinávia e aos $17 \%$ de vítimização encontrados na pesquisa realizada no Rio de Janeiro por Lopes Neto (2005, 2007). No entanto, este último autor ressalta a grande variabilidade dos estudos no que se refere aos índices de prevalência do fenômeno, que podem variar de 8 a $46 \%$ de vítimas, devido tanto às caraterísticas específicas das diferentes realidades pesquisadas, quanto a questões metodológicas. 
No que se refere a possíveis diferenças dos padrões de vitimização associadas ao sexo dos participantes, os dados indicam $28 \%$ das meninas e $20 \%$ dos meninos como possíveis vítimas de bullying. A ausência de diferenças significativas quanto aos sexos em termos de vitimização também tem sido observada em outras pesquisas realizadas no Brasil, como é o caso dos estudos de Bandeira e Hutz (2012) e Lopes-Neto (2005; 2007). É preciso levar em conta, entretanto, que, do ponto de vista dos agressores, estes relataram maior frequência de agressões a vítimas do sexo masculino, o que estaria de acordo com os dados de Olweus (1993). Deve-se estar atento, portanto, a possíveis diferenças na percepção do fenômeno por parte dos atores envolvidos, já que os agressores podem considerar alguns de seus comportamentos como brincadeiras. Nesse sentido, pensamos que, no caso de serem observadas incoerências no mapeamento do fenômeno, a percepção da vítima deveria prevalecer, uma vez que concordamos com Lisboa et al. (2009), os quais afirmam que um importante critério para a identificação da ocorrência de bullying é o sofrimento experimentado pela vítima.

Quanto ao perfil dos agressores, observou-se que, na escola pública, houve maior número de referências a agressões praticadas por meninos, enquanto na particular as agressões foram atribuídas de forma mais equilibrada a alunos de ambos os sexos. $\mathrm{O}$ fato de os meninos praticarem mais agressões diretas, enquanto entre as meninas predomina o padrão de bullying indireto, conforme atestam vários estudos (Olweus, 1993; Smith \& Sharp, 1995, apud Calbo et al., 2009) pode se responsável por estes resultados, uma vez que as humilhações e exclusões foram algumas das queixas de maior incidência na escola particular, enquanto na pública, os empurrões e agressões físicas tiveram uma frequência maior. No entanto, não podemos afirmar uma prevalência maior de um tipo de bullying em uma escola do que em outra, já que a diferença encontrada entre as escolas não foi estatisticamente significativa, com exceção das ofensas e calúnias, mais frequentes na escola particular. Além disso, houve também maior número de meninos se autorreportando como agressores. Tais resultados vão ao encontro dos obtidos por Olweus (1993), Lopes Neto (2005, 2007) e Bandeira e Hutz (2012), os quais concluíram que os meninos se envolvem, como agressores, em mais episódios de bullying do que as meninas, tanto contra alunos do mesmo sexo, quanto do sexo oposto.
É importante considerar que a atitude dos observadores tem grande importância, já que estes podem favorecer a ocorrência do fenômeno, servindo como reforçadores dos comportamentos agressivos, seja de forma direta ou indireta - rindo ou não fazendo nada a respeito. Nesse sentido, os resultados deste estudo, como os de Bandeira e Hutz (2012), mostram que a omissão por parte dos observadores ao presenciar as agressões é muito frequente, tanto nos relatos das vítimas quanto dos agressores, o que é bastante negativo, pois essa "aprovação silenciosa” (Salmivalli, 1999) não ajuda a diminuir o problema. Este, por sua vez, atinge os próprios observadores, os quais também são afetados em sua formação psicológica e moral pelo clima de insegurança, desrespeito, impunidade e banalização da violência que tais práticas suscitam.

No que se refere aos locais onde as agressões costumam ocorrer, os resultados indicam o recreio e a sala de aula como os mais frequentes, prevalecendo uma tendência a maior frequência de episódios durante o recreio na escola particular e na sala de aula, na escola pública (porém a diferença não foi estatisticamente significativa). Outros trabalhos sobre bullying, como o de Pereira, Silva e Nunes (2009) e Raimundo e Seixas (2009), também identificaram alta ocorrência de bullying durante o recreio nas amostras estudadas. Entretanto, chama a atenção a elevada frequência de agressões relatadas como tendo ocorrido em sala de aula, sobretudo na escola pública, sugerindo pouca ou inadequada intervenção dos professores com relação ao problema. Resultados dos estudos de Lopes Neto $(2005,2007)$ e Francisco e Libório (2008), realizados com alunos da rede pública, já haviam identificado esse problema, que parece mais grave no Brasil do que em outros países onde parece predominar o bullying em situações de recreio.

Outro resultado interessante é que, tanto vítimas quanto agressores, em sua maioria, têm a mesma idade e fazem parte da mesma turma, o que sugere a possibilidade de ações no interior das classes para minimizar o problema. Com efeito, algumas propostas de intervenção têm sido feitas direcionadas tanto ao nível escolar, como também da sala de aula e dos alunos e familiares diretamente envolvidos. Olweus (1993) descreve um programa de intervenção que consiste em medidas que podem ajudar a combater o bullying envolvendo a comunidade escolar como um todo. Um dos pré-requisitos é que haja uma conscientização do problema e envolvimento por parte dos 
adultos, sobretudo no ambiente escolar. Algumas das medidas ao nível escolar envolvem um mapeamento do problema através de questionário anônimo, um dia de "conferência escolar" (envolvendo equipe escolar, pais e alunos) para conscientização do problema, sua gravidade e consequências, e melhor supervisão durante intervalos e recreios. Já ao nível de medidas em sala de aula, algumas propostas como discutir e estabelecer regras a respeito do bullying e realizar grupos de discussão semanais entre os alunos podem ajudar na resolução do problema. Por fim, ao nível individual, algumas medidas como ter sérias conversas com vítimas e agressores, bem como com os pais dos alunos envolvidos, podem ser de grande ajuda.

Ainda abordando a estrutura e eficácia de programas para prevenir e combater o bullying em contexto escolar, podemos citar os estudos de Mendes (2011) em Portugal e de Fante (2005) no Brasil. O estudo de Mendes (2011) avaliou positivamente o impacto de um programa de intervenção voltado para a formação de docentes e pais e para o treino de competências sociais de estudantes (vítimas e agressores) em uma escola pública portuguesa. $\mathrm{O}$ programa foi aplicado a todos os estudantes de $5^{\circ} \mathrm{e}$ $6^{\circ}$ anos da escola e contou com as seguintes estratégias básicas: 1) Mapeamento do problema na unidade escolar, conscientização da escola e inclusão do programa no Projeto Pedagógico Escolar; 2) Formação dos professores da disciplina de Educação Cívica para trabalho em sala de aula com as turmas, visando à promoção de competências sociais (autocontrole e assertividade) e a redução/prevenção da violência escolar; 3) Reuniões dirigidas aos pais; 4) Aplicação do programa em sala de aula (intervenção com as turmas); 5) Intervenção com agressores e vítimas (realizadas pela psicóloga escolar). É importante considerar que o desenvolvimento de habilidades sociais como a empatia também deve ser considerado como possível estratégia de controle do comportamento agressivo dos alunos (Del Prette, \& Del Prette, 2005).

No Brasil, programas relatados na literatura como o "Educar para a Paz" (Fante, 2005) também têm sido aplicados com bons resultados. Em linhas gerais, esse programa propõe as seguintes etapas, a serem adaptadas em função das peculiaridades de cada escola: Etapa A Conhecimento da realidade escolar (inclui observações e aplicações de questionários, divulgação dos resultados e jornada sobre violência escolar); Etapa B - Modificação da realidade escolar, através de estratégias gerais, individuais, de sala de aula e familiares. A principal diferença com relação à estrutura geral do programa de combate ao bullying proposto por Olweus (1993) diz respeito ao programa brasileiro atribuir maior protagonismo e participação aos alunos na supervisão do problema, além de propor um serviço de denúncia escolar.

\section{Considerações Finais}

Dentre os resultados obtidos nesta pesquisa podemos destacar a elevada incidência de possíveis casos de bullying em ambas as escolas; a sala de aula como um dos locais mais frequentes de ocorrência das agressões (ao lado do recreio); a passividade da maioria dos observadores frente a episódios de agressão escolar, associada à percepção destas agressões como "brincadeiras", o que indica que muitas ações podem ser postas em prática a fim de minimizar o problema, prevenindo assim seus nefastos efeitos sobre a trajetória acadêmica e pessoal dos envolvidos.

Outro aspecto a ser considerado diz respeito à grande semelhança observada entre as escolas quanto à ocorrência de bullying, o que desmistifica explicações sobre a violência escolar que apontam fatores externos à escola - violência do bairro, educação dos pais, nível socioeconômico dos alunos - como sendo determinantes do problema, recuperando assim a responsabilidade da instituição escolar e de seus agentes no enfrentamento da questão.

No entanto, nenhum estudo está livre de limitações e, dessa forma, deve-se chamar a atenção para as deste estudo. Como os participantes foram alunos que se dispuseram a participar da pesquisa, é possível que a amostra possa ter sido um pouco enviesada, uma vez que o tema da pesquisa pode estimular a participação de alunos que tenham um maior envolvimento pessoal com o problema (sobretudo no caso das vítimas). Além disso, este é um estudo que se deu em apenas duas escolas, escolhidas por conveniência, de forma que não há a pretensão de promover uma generalização dos resultados aqui obtidos. Por fim, o número reduzido de participantes em ambas as escolas, especialmente na particular, pode ter dificultado a obtenção de significância estatística na análise de algumas das variáveis consideradas. Sugere-se, portanto, a realização de novas pesquisas sobre o tema, com amostras mais representativas. Além disso, o estudo da percepção de professores e pais acerca do problema também poderia ser uma forma de investigar mais a fundo o fenômeno. Por fim, mais pesquisas de intervenção, que testem os efeitos de programas destinados a minimizar o problema, também seriam importantes. 


\section{Referências}

Bandeira, C. M., \& Hutz, C. S. (2012). Bullying: prevalência, implicações e diferenças entre os gêneros. Psicologia Escolar e Educacional, 16(1), 35-44. https://doi.org/10.1590/S1413-85572012000100004

Calbo, A. S., Busnello, F. B., Rigoli, M. M., Schaefer, L. S., \& Kristensen, C. H. (2009). Bullying na escola: comportamento agressivo, vitimização e conduta pró-social entre pares. Contextos Clínicos, 2(2), 73-80. Recuperado de http://pepsic.bvsalud.org/scielo.php?script=sci_arttext\&pid=S1983-34822009000200001

Caravita, S. C. S., Di Blasio, P., \& Salmivalli, C. (2008). Unique and interactive effects of empathy and social status on involvement in bullying. Social Development, 18(1), 140-163. https://doi.org/10.1111/j.1467-9507.2008.00465.x

Del Prette, Z. A. P., \& Del Prette, A. (2005). Psicologia das habilidades sociais na infância: teoria e prática. Petrópolis, RJ: Vozes.

Fante, C. (2005). Fenômeno Bullying: como prevenir a violência nas escolas e educar para a paz. São Paulo, SP:Verus.

Francisco, M. V., \& Libório, R. M. C. (2008). Um estudo sobre bullying entre escolares do ensino fundamental. Psicologia: Reflexão e Crítica, 22(2), 200-207. https://doi.org/10.1590/S0102-79722009000200005

Freire, A. N., \& Aires, J. S. (2012). A contribuição da psicologia escolar na prevenção e no enfrentamento do Bullying. Revista da Associação Brasileira de Psicologia Escolar e Educacional, 16(1), 55-60. https:// doi.org/10.1590/S1413-85572012000100006

Freire, I. P., Simão, A. M. V., \& Ferreira, A. S. (2006). O estudo da violência entre pares no $3^{\circ}$ ciclo do ensino básico: um questionário aferido para a população escolar portuguesa. Revista Portuguesa de Educação, 19(2), 157-183. Recuperado de http://www.scielo.mec.pt/pdf/rpe/v19n2/v19n2a08.pdf

Lemos, A. C. M. (2007). Uma revisão psicopedagógica do bullying escolar. Revista Psicopedagogia, 24(73), 68-75. Recuperado de http://pepsic.bvsalud.org/scielo.php?script=sci_arttext\&pid=S0103-84862007000100009

Lisboa, C., Braga, L. L., \& Ebert, G.(2009). O fenômeno bullying ou vitimização entre pares na atualidade: definições, formas de manifestação e possibilidades de intervenção. Contextos Clínicos, 2(1), 59-71. Recuperado de http://pepsic.bvsalud.org/scielo.php?script=sci_arttext\&pid=S1983-34822009000100007

Lopes Neto, A. A. (2005). Bullying: comportamento agressivo entre estudantes. Jornal de Pediatria (Rio de Janeiro), 81(5 Supl), 164-172. https://doi.org/10.1590/S0021-75572005000700006

Lopes Neto, A. A. (2007). Bullying. Adolescência \& Saúde, 4(3), 51-56. Recuperado de http://www.adolescenciaesaude.com/detalhe_artigo.asp?id=101

Mendes, C. S. (2011). Prevenção da violência escolar: avaliação de um programa de intervenção. Revista da Escola de Enfermagem da USP, 45(3), 581-588. https:/ / doi.org/10.1590/S0080-62342011000300005

Moura, D. R., Cruz, A. C. N., \& Quevedo, L. A.(2011). Prevalência e características de escolares vítimas de bullying. Jornal de Pediatria (Rio de Janeiro), 87(1), 19-23. https://doi.org/10.1590/S0021-75572011000100004

Olweus, D. (1993). Bullying at school: what we know and what we can do. Oxford: Blackwell.

Olweus, D. (2011). Bullying at school and later criminality: findings from three Swedish community samples of males. Criminal Behaviour and Mental Health, 21(2), 151-156. https://doi.org/10.1002/cbm.806

Pastore, J., \& Silva, N. V. (2004). Nota sobre a mobilidade social no Brasil. In Seminário Especial: Mini-fórum em homenagem aos 40 anos do IPEA. Recuperado de http://www.inae.org.br/estudo/nota-sobre-a-mobilidade-social-no-brasil/

Pearce, J. B., \& Thompson, A. E. (1998). Practical approaches to reduce the impact of bullying. Archives of Disease in Childhood, 79, 528-531. https://doi.org/10.1136/adc.79.6.528

Pereira, B., Silva, M. I., \& Nunes, B. (2009). Descrever o bullying na escola: estudo de um agrupamento de escolas em Portugal. Revista Diálogo Educacional, 9(28), 455-466. Recuperado de http://www2.pucpr.br/reol/pb/index. $\mathrm{php} /$ dialogo?ddl=2826\&dd99=view\&dd98=pb

Raimundo, R., \& Seixas, S. R. (2009). Comportamentos de bullying no $1^{\circ}$ ciclo: estudo de caso numa escola de Lisboa. Interacções, 5(13), 164-186. Recuperado de http://revistas.rcaap.pt/interaccoes/article/view/402/356

Salmivalli, C. (1999). Participant role approach to school bullying: implications for interventions. Journal of Adolescence, 22(4), 453-459. https://doi.org/10.1006/jado.1999.0239 
Sposito, M. P. (2001). Um breve balanço da pesquisa sobre violência escolar no Brasil. Educação e Pesquisa, 27(1), 87-103. http://dx.doi.org/10.1590/S1517-97022001000100007

Luís Gustavo Faria Aguiar

Psicólogo, graduado pela Faculdade de Filosofia, Ciências e Letras de Ribeirão Preto (FFCLRP-USP). São Paulo-SP. Brasil. E-mail: luis.aguiar@usp.br

\section{Sylvia Domingos Barrera}

Profa. Dra. do Departamento de Psicologia da Faculdade de Filosofia, Ciências e Letras de Ribeirão Preto (FFCLRP-USP). São Paulo - SP. Brasil.

E-mail: sdbarrera@ffclrp.usp.br

Endereço para envio de correspondência:

Av. dos Bandeirantes, 3.900. CEP:14040-901.

Ribeirão Preto - SP, Brasil.

Recebido 03/08/2016

Reformulação 22/05/2017

Aprovado 13/06/2017

Received 08/03/2016

Reformulated $05 / 22 / 2016$

Approved 06/13/2007

Recebido 03/08/2016

Reformulado 22/05/2017

Aceptado 13/06/2017

Como citar: Aguiar, L. G. F., \& Barrera, S. D. (2017). Manifestações de bullying em diferentes contextos escolares: um estudo exploratório. Psicologia: Ciência e Profissão, 37(3), 669-682. https://doi.org/10.1590/1982-3703002922016

How to cite: Aguiar, L. G. F., \& Barrera, S. D. (2017). Manifestations of bullying in different school contexts: an exploratory study. Psicologia: Ciência e Profissão, 37(3), 669-682. https://doi.org/10.1590/1982-3703002922016

Cómo citar: Aguiar, L. G. F., \& Barrera, S. D. (2017). Manifestaciones de bullying en diferentes contextos escolares: un estúdio exploratório. Psicologia: Ciência e Profissão, 37(3), 669-682. https://doi.org/10.1590/1982-3703002922016 